\title{
CORRIGENDUM
}

\section{Modifiable environmental influences on body mass index shared by young adult brothers}

B Rokholm, K Silventoinen, P Tynelius, TIA Sørensen and F Rasmussen

International Journal of Obesity (2013) 37, 323; doi:10.1038/ijo.2012.188

Correction to: International Journal of Obesity (2013) 37, 211-215; doi: 10.1038/ijo.2012.151

Since the advance online publication of this article, the authors have noticed an error in the results section of the abstract. It should read as follows:

Intraclass correlation for BMI in dizygotic twin pairs was higher (0.431, 95\% confidence interval (Cl) 0.394-0.466) than the correlation for full-brothers in the first quartile of birth-year difference $(0.376, \mathrm{Cl} 0.342-0.408)$. Among full-brothers, the BMI correlation decreased from $0.376(\mathrm{Cl} 0.342-0.408)$ in the first quartile to $0.338(\mathrm{Cl} 0.331-0.345)$ in the last quartile.

This error has now been rectified and the corrected article appears in this issue. The html and online PDF versions have also been amended.

The authors would like to apologise for this error. 